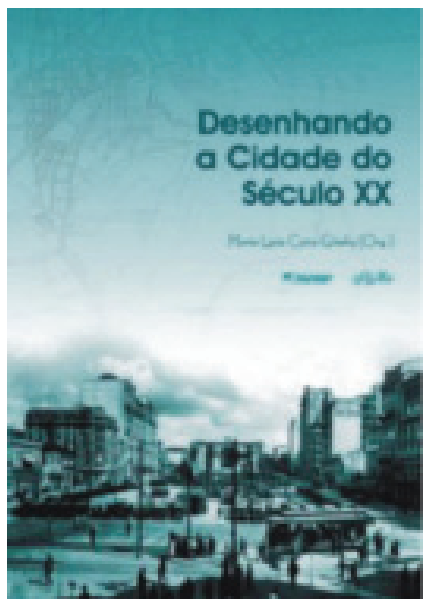

\title{
DESENHANDO A CIDADE DO SÉCULO XX
}

GitaHY, Maria lucia caira. são carlos: RIMA/FAPESP. 2005.

ISBN 85-7656-OII-9, I48 P.

\section{Júlio Roberto Katinsky}

\section{UM LIVRO INOVADOR DA FAUUSP}

O livro organizado pela professora Maria Lucia Caira Gitahy, tendo como capítulos ensaios de seus alunos, ultrapassa em importância o conteúdo explícito das contribuições e pode ser considerado, quem sabe, um ato inaugural. Isso porque é também o registro de uma equipe de pesquisa com projeto comum, qual seja estabelecer um quadro coerente, por assim dizer, da ocupação territorial e da construção da cidade de São Paulo no período republicano, entre 1880 e 1950.

Nesse sentido, esta resenha pretende ser um intróito (isto é, convite à leitura), pois será desejável que seu exemplo frutifique em outros projetos de pesquisa da ocupação do território brasileiro. É preciso, entretanto, ressaltar que a inovação consiste antes na reunião explícita e sistemática das pesquisas, pois, rigorosamente, todos os pesquisadores, professores do curso encaminham-se, mesmo implicitamente, para essa postura.

O livro, então, compreende uma apresentação da pesquisadora Maria Irene Szmrecsanyi, na qual se justifica toda a pesquisa como uma contribuição dos vários protagonistas históricos em suas palavras:

"dirigentes do Estado que se conectam com os do capital e trabalhadores em busca de melhoria de condições de vida, muito embora ambos cooperem na modernização dos espaços urbanos e rurais, um grupo pretendendo o usufruto de melhores condições de habitabilidade e o outro promovendo aquelas que the garantissem benefícios econômicos".

O objetivo, entretanto, situa-se naquilo que a apresentadora define como conquista da "modernização":

"Em sua origem européia, a modernização geralmente é concebida como o longo processo de conquista da hegemonia pelo pensamento secular racional filosófico cientifico e da ordem social burguesa, sob a égide dos avanços da economia capitalista."

A introdução da organizadora, Maria Lúcia, expõe a rede de conceitos dentro da qual se pretende capturar o sentido das decisões e ações dos grupos sociais que aqui agiram e interagiram para garantir ao país, nas relações externas e internas, como participante do mercado mundial e dos benefícios que este possa oferecer para a sociedade brasileira. Esse estudo, por uma questão de método científico, restringe-se 
ao período 1880-1950 aproximadamente, no qual se verifica não só um extraordinário incremento demográfico, mas também uma intensa urbanização.

O livro se compõe de seis capítulos; o primeiro, de Luis Augusto Maia Costa, Planejando antes do planejamento; o segundo, Território e cidade em São Paulo 1880-1910, de Sidney Piochi Bernardini sobre o plano sanitário para Santos, do engenheiro norte-americano Estevan A. Fuertes. O terceiro, de Cristina Campos, sobre a atuação do médico sanitarista Geraldo Paula Souza (1922-1945). O quarto capítulo, de Carlos Augusto da Costa Niemeyer, aborda os espaços públicos lúdicos da cidade sob o título Do velódromo aos parques infantis - Paradigmas e contradições na produção social dos espaços lúdicos em São Paulo.

Os dois últimos capítulos, de Marcos Virgilio da Silva, São Paulo - 1946-1957: Representações da cidade na música popular e de André Augusto de Almeida Alves, São Paulo debate o moderno, 1956-1968: Um projeto de pesquisa, referem-se a uma primeira proposta para inventariar e registrar como os próprios habitantes reagiram, do ponto de vista de expressão, aos fenômenos ocorridos no território paulista.

O primeiro capítulo, na realidade, não se refere à expansão geográfica de São Paulo senão como dependente da ocupação do território do estado (praticamente nos limites atuais, pois o Paraná já estava separado de São Paulo desde 1850). Nesse sentido, o capítulo centra toda a ocupação do oeste paulista a partir de 1870, em dois fatos relevantes: abolição da escravatura e a conseqüente imigração subsidiada pelo Estado, a serviço de uma "burguesia agrária" que iria tornar possível a vertiginosa produção cafeeira paulista da época. Pois entre 1850, quando o café suplanta o açúcar na exportação por Santos (Maria S. Petrone) e 1890, a produção paulista correspondia a mais de $2 / 3$ da produção mundial.

Ou, nas palavras do autor:

"Contudo a execução de um plano geral ainda não estava posta como uma necessidade, pois somente um debate entre os profissionais da área teria sido realizado na época. Como só agora esse plano vem à tona e passa a ser debatido, confirmam-se nossas suspeitas anteriores de que planos gerais para a capital do Estado de São Paulo, não eram um problema socialmente posto. O problema não estava em desenhar o urbano, mas em planejar o Estado territorialmente. A forma urbana seria uma conseqüência, estaria muito mais relacionada ao papel de tal cidade na articulação territorial." (p. 15)

Parece-me que poderíamos acentuar mais essa postura dos planos gerais para a cidade não encontrar eco na inteligência técnica da cidade, se não mesmo uma certa desconfiança entre "plano" e "centralização" de poder vista como um freio ao desenvolvimento das forças produtivas. É o que observa Adolpho Augusto Pinto em sua obra fundamental: História da viação pública de São Paulo, 1903, na p. 21.

\section{As Quatros fases do DesenVolvimento Ferroviário - CARACTERES DISTINTIVOS}

"Pode-se dividir em quatro fases perfeitamente distintas a época decorrida desde as primeiras tentativas para a construção do caminho de ferro até o pleno desenvolvimento e aclimação em São Paulo, desse maravilhoso meio de transporte.

A primeira fase, como de ordinário só e acontecer em semelhante ordem de fatos, é a dos ensaios malogrados, é o período dos percursos mais ou menos fantasistas, 
daqueles que não raro tendo tudo sacrificado ao seu ideal, menos felizes que Moysés, nem sequer conseguem morrer à vista da canaã de sua suprema aspiração.

A segunda fase, de notáveis resultados positivos, caracteriza-se pelas concessões ferroviárias feitas com os favores de zona privilegiada e garantia de juros.

Na terceira fase as estradas ainda se constroem com o privilégio de zona, mas já dispensam a garantia de juros.

Finalmente sobrevém a quarta fase, definida pelo regime de plena liberdade: a indústria ferroviária em completo desenvolvimento emancipa-se da proteção do Estado, tornando-se livre a qualquer construção de estradas de ferro, com a única restrição de respeitarem-se os direitos adquiridos". (p. 21)

\section{TRAÇADO GERAL DAS ESTRADAS DE FERRO}

"Como em outro lugar tivemos ocasião de dizer, o desenvolvimento das estradas de ferro em São Paulo não obedeceu a um plano geral previamente delineado; as malhas da grande rede de viação ligeira, que hoje cobre a porção mais rica e povoada do Estado, foram sendo tomadas dia a dia, sem nenhuma preocupação de conjunto, sem sistema ou coordenação de partes visando um certo resultado geral, ao menos nos primeiros tempos."

"Em verdade, é motivo para justas congratulações reconhecer que, apesar de não ter presidido à sua primeira formação um princípio geral de método, entretanto as linhas férreas de fato se desenvolveram por modo a virem as suas partes a formar mais tarde um sistema geral relativamente bem delineado, o qual, com bem poucas modificações seria o próprio que conviria traçar hoje sobre o mapa do Estado, se porventura fosse possível apagar a obra feita para substituí-la por outra." (p. 85)

Evidentemente, não cabe estudar exaustivamente o importante trabalho de Augusto Pinto, mas não se pode deixar de notar a postura diametralmente oposta àquela expressa no livro de Cristiano Benedito Ottoni, O futuro das estradas de ferro no Brasil (1869), no qual o autor, engenheiro militar, preconizava para o Brasil um plano geral, para os meios de transporte nos quais se combinavam objetivos econômicos e estratégicos nacionais, provavelmente apoiados nos politécnicos saint simonianos. Diga-se de passagem que a rede ferroviária francesa, iniciada em 1840, manteve-se, devido ao apuro técnico conseguido, um dos mais impressionantes êxitos do projeto socialista francês até nossos dias, mantendo a indústria ferroviária francesa posição imbatível na vanguarda tecnológica mundial.

Na verdade, à luz da obra de Augusto Pinto, principalmente, podemos traçar os limites do planejamento estatal aceito pelos positivistas e liberais que assumiram o poder em São Paulo com a República: saúde pública e educação. Mesmo o abastecimento de água foi pensado, inicialmente, como um serviço entregue à iniciativa privada. A própria Light se instalou em São Paulo, em seguimento a várias iniciativas locais, das quais sobressai a Companhia Paulista de Força e Luz, de Rio Claro, e a Companhia Paula Souza (termoelétrica).

Também não se pode reduzir à "oligarquia do café", homogeneamente, a condução ideológica e política das diretrizes que balizaram o desenvolvimento do estado. Convém não esquecer que, em 1859, os mesmos senhores de terra e 
fazendeiros de café fundaram a Fábrica São Luiz que produziu tecidos até a década de 60 do século passado. Alguns nomes como Anhaia Mello, Paula Souza, tanto comparecem na fundação de uma das primeiras tecelagens maquinofatureiras do país como na fundação da Escola Politécnica em 1894, uma das mais qualificadas escolas técnicas da América, na época. A industrialização paulista foi objeto de notáveis estudos de Roberto Simonsen, mas no plano regional não podemos omitir os estudos de Nardy Filho (1949), Dean (1976) e Zequini (2004). E esse fenômeno continuou ocorrendo durante todo o século 20. Constantino lanni, em um estudo para o plano diretor de 1967 para Itu, constatou surpreso que as poupanças agrícolas nos bancos da região eram aplicadas no comércio da cidade e na indústria local.

Que a imigração dos anos 80 e 90 trouxe perturbações no relativamente bemarrumado cenário previsto por seus promotores não há dúvida, mesmo porque as expectativas eram opostas. Flavio Motta estudou esse conflito nos versos de Cornélio Pires, um poeta caipira muito mais prestigiado pelos oriundi do que pelos representantes da grande (!) literatura paulista.

Dona Marina Pacheco, fazendeira e matriarca notável da família, uma vez me contou que conheceu algumas primas-irmãs, filhas de um tio seu, quando freqüentou o Colégio do Patrocínio (c.1910), pois esse parente próximo tinha se casado com uma "italianinha" e, portanto, tinha sido banido do convívio familiar.

Histórias como essa se contam em muitos casos, mas duram pouco. O que se prolongou por muitos anos foi a "divisão de tarefas" em São Paulo: as poupanças dos donos da terra foram aplicadas no parque ferroviário paulista, no grande comércio, na produção de bens de capital. A poupança dos imigrantes foi dirigida, principalmente, para produção de bens de consumo, incrementando o incipiente mercado interno predominantemente desenvolvido de São Paulo para o Sul do país.

Em nota de pé de página (p. 15) anota-se que, em um projeto de iniciação científica, possivelmente, o aluno Luis Felipe Bernardini está iniciando o levantamento sistemático de fontes sobre o engenheiro Adolfo Augusto Pinto. Penso que seria extremamente valioso reunir os escritos do eminente engenheiro, típico representante de uma proposta industrialista, e colocá-los à disposição dos estudiosos na biblioteca da FAU. Há anos o senhor Arrobas Martins, quando chefe da Casa Civil do Estado, reeditou valiosos trabalhos sobre São Paulo, entre eles o livro aqui citado, do funcionário graduado da Companhia Paulista. Infelizmente nenhum desses exemplares foi incorporado à biblioteca da FAU, tendo nós de utilizarmos uma precária antiga e incompleta cópia xerox do exemplar do IPHAN de São Paulo.

Os capítulos 2, 3 e 4 seguem com suas contribuições, o quadro explicativo proposto, e são, penso eu, uma grande contribuição da Faculdade de Arquitetura e Urbanismo (haja vista suas respectivas bibliografias) para a historiografia dos fenômenos recentes da história do Brasil. Não devemos, entretanto, omitir os estudos das orientandas da professora Maria Amélia Dantes sobre a instalação (e institucionalização) da ciência no final do século 19 em São Paulo.

Gostaria, todavia, de deter-me no capítulo 5, pois há uma literatura característica, creio eu, das grandes cidades como São Paulo, e que pode ser, em alguns casos, tímida, outras agressiva, sempre, contudo caracterizada como reinvidicadora do ponto de vista social. Começa em São Paulo com Silvio Floreal (pseudônimo) e Juó Bananere ou Marcondes de Madame Pommery na década de 20, ou ainda Afonso Schmidt na mesma época, mas vem até nossos dias (Quarto de 
despejo - Capão pecado). Essa literatura, que chamo de suburbana negligenciada pelos críticos literários, deve existir em muitas cidades do porte de São Paulo.

Aqui também não terá contribuído para a consciência da urbanização?

Algumas observações finais me parecem pertinentes: não é o café que explica a ocupação territorial paulista, mas o contrário. Ou seja, enquanto a implantação do açúcar nordestino foi estabelecida dentro da estratégia imperial portuguesa para fixar populações afinadas com objetivos de garantia da posse do território, o mesmo não se pode dizer das populações fixadas em dois povoados paulistas, São Vicente e Santo André da Borda do Campo, que aconteceram, muitos anos antes da chegada do primeiro donatário.

Até 1720 , as atividades econômicas vicentinas foram periféricas em relação ao povoamento nordestino e mineiro. A instalação da manufatura açucareira no planalto, o mercado de muares em Sorocaba, ainda foi desenvolvido em função das Minas Gerais, de Mato Grosso e Goiás. Só depois de 1760 o açúcar paulista passa a ser desviado para o porto de Santos. Mas, já nessa época, as grandes vias de um mercado interno, autônomo (até onde era possível) estavam instaladas. O café, como mostrou a senhora Maria S. Petrone (A lavoura canavieira em São Paulo), instalou-se no norte e nordeste paulistas, beneficiando-se de uma infra-estrutura produzida pelo açúcar. Ou seja, o café ocupou, em um primeiro momento, o Vale da Paraíba do Sul, o qual chamo de café monárquico e a região de Itu, Sorocaba, Campinas, Jundiaí, o celebre "quadrilátero do açúcar", de Caio Prado Júnior, e que pode ser chamado café republicano, com efeitos opostos. Ou seja, a "aligarquia cafeeira" estava longe de ser homogênea, e pelo menos uma fração dela estava comprometida com a industrialização e com a institucionalização da ciência e da tecnologia.

O café monárquico só produziu "cidades mortas", de acordo com Monteiro Lobato e Cornélio Penna. O café republicano produziu os grandes institutos de pesquisa, a discussão dos problemas brasileiros, a industrialização com algum aporte tecnológico e a primeira universidade marcada pela pesquisa.

Mas não podemos reduzir a história às suas determinantes econômicas e geográficas. Nesse sentido, os livros de Carlos Guilherme Motta (Idéia de revolução no Brasil - 1789-1801) e Fernando Novais (Portugal e Brasil na crise do antigo sistema colonial - 1770-1808) são também valiosas balizas para se entender o que ocorreu no país no início do século 20, ao lado de Caio Prado Júnior (Evolução política), Sergio Buarque (Visão do paraíso) ou Dante Moreira Leite.

Mesmo porque, como explicar a atuação do íntegro Caio Prado Júnior, introdutor das análises apoiadas no filósofo e cientista alemão Karl Marx, sendo ele membro, na época, da poderosíssima família detentora de uma das mais ricas empresas do continente, a firma Prado \& Chaves. Além dos interesses de classe, a integridade e outros valores agasalhados por nossa civilização, também são protagonistas da história.

Essas observações só acentuam, a meu ver, a importância do livro em questão, e sugerem um valioso debate, que, esperamos, irá contribuir para a compreensão de nossa realidade, matéria-prima de nossa ação futura.

Júlio Roberto Katinsky

Professor titular do Departamento de História da Arquitetura e Estética do Projeto e professor orientador do curso de pós-graduação da FAUUSP. 